\title{
M.О. Тяпкин
}

\section{ОХРАНА ЛЕСОВ НА ЮГЕ ЗАПАДНОЙ СИБИРИ В ПЕРВОЙ ПОЛОВИНЕ 1918 г.}

Рассматривается реализация лесоохранных мероприятий в Алтайской и Томской губерниях в период кратковременного установления советской власти в первой половине 1918 г. Основными направлениями деятельности в сфере охраны лесов являлась борьба с самовольными порубками и лесными пожарами. Противодействие самовольным порубкам, а также борьба с лесными пожарами были возложены на местные органы советской власти. Основной идеей являлось обобществление обязанностей по охране лесов, объявленных общенародным достоянием. За непродолжительный период руководства земельно-лесным хозяйством региона советская власть не внесла кардинальных перемен в систему лесоохраны. После перехода власти к Временному Сибирскому правительству все нововведения советов и принятые ими нормативные акты были отменены.

Ключевые слова: лесоохрана; национализация; самовольная рубка леса; лесные пожары; народная лесная стража; советская власть.

Одним из важнейших направлений модернизации социально-экономической сферы российского общества в дореволюционный период являлся поиск способов решения земельного вопроса и его составляющей - вопроса о лесных ресурсах страны, их эксплуатации и охране. Смена политического режима, произошедшая в России в результате революционных событий 1917 г., поставила перед властью и обществом задачу формирования новой государственной лесной политики, важнейшей частью которой должна была стать организация лесоохраны.

Отдельные аспекты заявленной нами темы рассматривались историками в рамках изучения аграрной политики государства и ее реализации в период революционных событий и последовавшей за ними Гражданской войны. Безусловно, при изучении аграрной истории, в том числе способов решения земельного вопроса, невозможно уйти от аспектов, связанных с лесохозяйственной деятельностью. Вместе с тем лесоохрана должна рассматриваться в качестве самостоятельного предмета исследования, особенно на примере такого региона, как юг Западной Сибири, где в дореволюционный период сложилась достаточно развитая система лесного хозяйства. Региональный аспект лесоохраны изучается нами на основе привлечения разнородных исторических источников, преимущественно архивных материалов, многие из которых вводятся в научный оборот впервые.

После октябрьской революции началось формирование новой государственной лесной политики, в основу которой был положен принцип национализации и социализации земель и лесов, провозглашенный декретом II Всероссийского Съезда Советов рабочих, солдатских и крестьянских депутатов «О земле» (27 октября 1917 г.) [1. С. 4-6]. Относительно лесов декрет, а точнее, его часть «Крестьянский наказ о земле», закреплял норму, согласно которой «леса и воды, имеющие общегосударственное значение, переходят в исключительное пользование государства. Все мелкие реки, озера, леса и проч. переходят в пользование общин при условии заведывания ими местными органами самоуправления» [2. С. 10] Лес был объявлен всенародным достоянием, что повлекло за собой коренной пересмотр содержания всех элементов лесохозяйственного механизма.

Реализация решения о национализации земли привела к тому, что за сибирскими крестьянами были закреплены те земли, которые находились в их пользовании, являясь собственностью казны или Кабинета ЕИВ. Самовольные захваты крестьянами бывших арендных участков и казенных оброчных статей, начавшиеся еще весной 1917 г., после объявления о национализации активизировались. На крестьянских волостных и уездных съездах самыми обсуждаемыми становились вопросы «о власти и земле с лесными угодьями» [3. С. 39]. После установления в регионе советской власти самовольные захваты были узаконены. Оказались захваченными многие сенокосные и пашенные участки, находившиеся в пользовании лесной администрации и лесной стражи, что дало почву для новых конфликтов лесников и объездчиков с крестьянами, а в некоторых лесничествах поставило лесную стражу на грань выживания. В условиях экономического кризиса и катастрофического обесценивания денег личные подсобные хозяйства лесников и объездчиков являлись в некоторых случаях единственным источником средств к существованию. В некоторых лесничествах для предотвращения голода среди служащих руководство стало практиковать централизованную закупку продовольствия, выделяя на это часть средств из лесных доходов.

После февральской революции практически во всех регионах страны колоссальные масштабы приобрели самовольные порубки леса. Уже в начале весны 1917 г. лесничие в своих докладах отмечали, что население повсеместно «путает» государственный лес с крестьянским и не видит между этими понятиями отличий [4. Л. 58]. Как в период первой русской революции, так и в 1917 г. объявление гражданских свобод было воспринято большинством населения как одобрение вседозволенности. «Масла в огонь» подлило Временное правительство, которое в марте 1917 г. приняло ряд указов, постановлений и деклараций об амнистии, в том числе по делам о лесонарушениях [5. C. 99]. Пока на страницах периодической печати и заседаниях профессиональных лесоводческих форумов решалось будущее отечественного лесного хозяйства, леса уничтожались «ударными» темпами.

Западная Сибирь с ее богатейшими ресурсами приобретала для центральной власти особое значение. После заключения мира с Германией, оккупации Украины немецкими войсками и начала Гражданской войны центральная часть страны и обе столицы ока- 
зались отрезаны от продовольственных запасов. Центр рассчитывал превратить Западную Сибирь в хлебную житницу страны. Большие надежды возлагались на сибирские леса, которые должны были стать важнейшей статьей экспорта и источником формирования доходной части государственного бюджета. Проблема удовлетворения внутренних потребностей в древесине, прежде всего в топливе, возникшая еще во время Первой мировой войны, после революции вылилась в жесточайший топливный кризис. Древесина становилась стратегическим материалом, а после потери советской властью угольных месторождений Донбасса - практически единственным средством обеспечения работы железнодорожного транспорта, промышленных предприятий, поддержания жизни учреждений и граждан в замерзающих городах. Решить эту проблему удалось ценой колоссального увеличения эксплуатационной нагрузки на лесные массивы в ущерб принципам рационального ведения лесного хозяйства и неистощительного лесопользования. Не случайно В.И. Ленин утверждал, что «лес спас революцию».

Перед местными органами советской власти и лесотехническими специалистами (так стали именоваться представители бывшей лесной администрации) была поставлена задача сохранения лесных ресурсов от бесконтрольного лесопользования и сокращения потерь от лесных пожаров. Охрана лесов была объявлена всеобщей гражданской обязанностью, поэтому задача по организации и осуществлению лесоохраной деятельности была возложена на местные советы. Непосредственное управление лесами должны были осуществлять земельные отделы исполнительных комитетов советов, а за бывшей лесной администрацией оставались чисто технические функции. Без участия специалистов, имеющих специальное образование, ведение лесного хозяйства было бы невозможным, поэтому местные советские учреждения предупреждались центром о недопустимости их необоснованного увольнения.

В октябре 1917 г. начинается период, продолжавшийся до февраля-марта 1918 г., который В.И. Ленин называл «триумфальным шествием советской власти». В соответствии с установкой центра на монополизацию власти советскими органами советы на местах стремились подчинить себе все учреждения административного, хозяйственного, финансового и культурно-просветительского значения [1. С. 190191]. Следуя этим руководящим предписаниям, советские структуры Алтайской и Томской губерний взяли курс на ликвидацию существовавшей административно-хозяйственной системы и замену ее новыми коллегиальными органами. Достаточно укрепившись и устранив своих политических конкурентов, прежде всего земские учреждения, от управления национализированными земельно-лесными ресурсами в Западной Сибири к весне 1918 г., советы оказались вынуждены самостоятельно решать вопросы охраны лесов. Мероприятия, осуществляемые советской властью в сфере лесного хозяйства на юге Западной Сибири, являлись частью новой общегосударственной лесной политики. Свое концентрированное выраже- ние она получила в принятом 27 (14) мая 1918 г. декрете ВЦИК РСФСР «О лесах», практически сразу получившем неофициальное наименование «Основной закон о лесах». Он был подготовлен в развитие норм декрета «О социализации земли».

Декрет «О лесах» определил основные направления развития советского лесного хозяйства, в том числе в сфере лесоохраны. На всех граждан советской республики была возложена обязанность «всеми доступными средствами охранять леса от пожаров, потрав, порчи, нападения насекомых и т.п. и принимать все меры к заботливому отношению к общенародному благу» [1. С. 567-580]. Этим же нормативным актом предусматривалась возможность привлечения любого гражданина по требованию советской власти к временному исполнению общественных обязанностей и службе по охране лесов как при общественных лесных бедствиях (например, пожары, нападение насекомых), так и в другое время. Участие в общественных лесных работах, а в случае невозможности личного участия - внесение специального лесного сбора, было названо необходимым условием для получения от государства строевой и дровяной древесины.

Первоначально лесная политика советской власти характеризовалась значительными уступками крестьянству в вопросах лесопользования и принятием таких решений, которые находили отклик у населения, однако могли идти вразрез с интересами лесного хозяйства. Был установлен новый порядок основного и побочного лесопользования и отпусков лесных материалов потребителям. Лесоотпускные таксы для железных дорог и коммерческих предприятий по сравнению с существовавшими с 1916 г. увеличивались в три раза, а при отпуске леса на общественные нужды и для населения предусматривались льготы в виде понижения таксовой стоимости, а также бесплатный отпуск для нужд «отдельных, единичных, бедных домохозяев, острая нужда которых в лесных материалах и бедное состояние зафиксированы в общественном приговоре» [6. Л. 22 об.]. Право понижать стоимость леса при продаже его населению и выносить решение о бесплатной выдаче лесоматериалов получали земельно-лесные управы. Единственным ограничением объемов льготных или бесплатных отпусков являлось условие, чтобы размер отпускаемой древесины не превышал годового отпуска из лесной дачи. За нецелевое использование полученного или приобретенного по льготной цене леса, в частности за его перепродажу, предусматривалось взыскание с нарушителя штрафной таксовой стоимости лесоматериалов.

Правом получения бесплатно валежника стали обладать все категории населения, в отличие от дореволюционного периода, когда подобную привилегию имели только малоимущие семьи солдат, призванных в действующую армию [6. Л. 25-25 об.]. Безусловно, система льготного лесоотпуска всегда рассматривалась как способ снижения остроты лесного вопроса путем удовлетворения нуждающихся в древесине законным путем, однако в условиях глубочайшего кризиса меры по увеличению социальной нагрузки на лесную отрасль себя не оправдывали [7. С. 165-170]. Доходы от отпусков лесных материалов резко сокра- 
щались, а «расходы по управлению, устройству, охранению и эксплуатации лесов в связи с чудовищным ростом современной дороговизны с каждым днем возрастают все в большей и большей степени, в настоящее время уже достигают огромных многомиллионных сумм, превышающих расходы довоенного времени во много раз» [6. Л. 29]. В результате местные власти были вынуждены повысить таксовую стоимость лесных материалов для всех категорий лесопользователей.

По мере нарастания топливного кризиса указания, приходившие из центра, все более жестко требовали не допустить истребления лесов. В целях повышения эффективности лесоохранной деятельности было предложено увеличить объемы финансирования этого направления. Так, в Алтайской губернии на 1918 г. предлагалось увеличить штат объездчиков на 90 человек (30 старших и 60 младших) и выделить на содержание лесной стражи на 2097670 руб. больше сметы 1917 г. (всего 2629800 руб.). Кроме того, планировалось выделение 38500 руб. на особые расходы по надзору за самовольными порубками (найм «летучих отрядов»), что было больше запланированного в 1917 г. на 31300 руб. [8. Л. 2-2 об.].

К весне 1918 г. самовольные порубки на юге Западной Сибири приобрели, по отзывам лесничих, «беспощадный» характер. Борьба с самовольными порубками становилась все более сложной и приобретала политический подтекст. Провозглашение лесов общенародным достоянием было понято населением, долгое время находившимся в состоянии конфронтации с администрацией по вопросам лесопользования, слишком буквально. Преследование самовольных порубок воспринималось крестьянами как ущемление гражданских прав и свобод, провозглашенных революцией.

В лес выезжали целыми селами на десятках подвод. Разгоняли лесную стражу и рубили лес без ограничений и правил, выбирая спелый строевой лес. Так, в Верх-Обском лесничестве Алтайской губернии в начале 1918 г. были вырублены все семенные деревья, оставленные на гарях в рамках реализации программы лесовозобновления. Иногда объездчиков угрозами заставляли выдавать билеты на рубку леса и клеймить самовольно вырубленный лес, чтобы придать некую легитимность своему промыслу и избежать возможной конфискации древесины [4. Л. 113]. Жители приборовых сел и деревень активно включились в строительство жилья и подсобных построек из свежесрубленного леса. При этом в ход пошел лучший лес, который не предназначался к отпуску, а составлял стратегический запас лесничеств. Для многих крестьян появилась возможность заняться прибыльным промыслом - продавать самовольно срубленный или полученный на льготных основаниях лес в отдаленные от боров населенные пункты.

Учет вырубленного леса был крайне затруднен, а чаще всего просто невозможен. Кроме того, значительная часть подобных сведений была уничтожена в ходе погромов контор лесничеств и кордонов лесной стражи. По оценкам лесничих, леса было вырублено такое количество, что некоторые дачи, в особенности боровые, можно было уже не считать лесными. Остро стоял вопрос об искусственном облесении вырубленных участков, так как появление на них песков грозило экологической катастрофой.

Весной 1918 г., после того как снег стаял и зимние дороги для вывозки леса стали непригодными, в лесах открылась неприглядная картина. Лесные дачи оказались завалены лесным мусором, порубочными остатками, а также приготовленными, но не вывезенными бревнами. Бревна лежали не только в лесу, но и на кордонах, куда их привозили сами крестьяне для клеймения. По распоряжению лесничих такая древесина поступала под охрану лесной стражи с дальнейшей продажей на лесных торгах. Осенью 1918 г., когда политическая ситуация в регионе уже поменялась, лесничим было предписано продавать самовольно вырубленный лес тем же порубщикам, но с уплатой ими по таксам 1916 г. тройной стоимости древесины [9. Л. 12].

Лесничие обращались в уездные и волостные земельные комитеты, а позже советы крестьянских и солдатских депутатов с просьбами оказать содействие прекращению самовольных порубок и угроз страже и принять меры для защиты от «беспощадного истребления общенародного достояния» [9. Л. 9 об.-10; 10. Л. 5 об.]. Какой-либо существенной помощи местные власти оказать не могли. Так, Усть-Пристанский совет Алтайской губернии предложил Верх-Обскому лесничему В. Родзевичу прислать в его распоряжение летучий отряд, состоящий из двадцати солдат, но за особую плату в размере 25 руб. каждому солдату. Средств на оплату «услуг» вооруженного отряда у лесничего не оказалось. Часть полномочий по охране лесов была возложена на милицию, однако какоголибо положительного эффекта это не дало.

Наиболее законопослушная часть деревни сама обратилась к городу с призывом восстановить порядок [11. Л. 28-28 об., 84, 134-135, 164-165]. Отдельные сельские общества пытались поставить под свой контроль массивы, располагавшиеся в непосредственной близости от них, что приводило к конфликтам между жителями приборовых селений и тех, кто проживал в безлесной местности.

Рост числа самовольных порубок воспринимался советской властью очень болезненно, поэтому к порубщикам применялись достаточно жесткие меры. Например, Славгородский уездный совет весной 1918 г. постановил привлекать самовольных порубщиков без суда и следствия к значительным штрафам или тюремному заключению до 3 лет. Сельским обществам было дано право устанавливать для своих членов, виновных в самовольной порубке, дополнительные штрафные санкции. При этом необходимо признать, что сил и средств для реализации подобных карательных мер у местных властей было крайне мало.

Важнейшим фактором борьбы с самовольными порубками являлось состояние нижнего звена лесоохранного механизма - лесной стражи. Она являлась для населения олицетворением старой административно-хозяйственной машины со всеми ее недостатками. Старший лесничий Алтайского округа К.П. Перетолчин в своих воспоминаниях приводит случай, 
произошедший с ним весной 1917 г., когда он вместе с другими представителями лесной администрации был отправлен в командировку «для личных переговоров по вопросам земельно-лесного хозяйства» с земельными комитетами [12. Л. 643]. Во время одной из поездок у него состоялся диалог с крестьянкой: «Из Тальменки мы поехали в Чингисы. Нас везла одна женщина, взамен ямщика, и вот дорогой она говорит: “А чего же это царя-батюшку спихнули? Это ведь не он виноват, а объездчики!”» [13. Л. 250]. Именно на объездчиков и лесников выплеснулось все народное недовольство существовавшей до революции системой лесопользования. Лесную стражу выгоняли из казенных кордонов, уничтожали имущество, применяли физическое насилие, убивали. В результате началось массовое бегство лесников и объездчиков со службы.

Проблемы с кадровым составом лесной стражи обозначились еще во время Первой мировой войны и были связаны с мобилизацией лесников и объездчиков в действующую армию. Весной и летом 1917 г. под давлением со стороны местного населения началась массовая замена постоянной лесной стражи на выборную, устраивавшую крестьян. Осенью 1917 г. исполнительный комитет Томского народного собрания и Томский губернский земельный комитет разработали правила, определявшие порядок выбора и назначения временной лесной стражи [14. Л. 15; 15. Л. 8-8 об.]. При появлении вакантных должностей лесной стражи лесничие были обязаны уведомлять об этом волостные земельные комитеты, в распоряжении которых был месяц для поиска подходящего кандидата. Лесничий в случае несогласия с предложенным кандидатом мог вынести вопрос на рассмотрение уездной земельной управы, а также назначить «своего» кандидата при отсутствии предложений со стороны местных комитетов. Решение лесничего о приеме на работу или увольнении лесника (объездчика) подлежало утверждению приказом управляющего государственными имуществами или начальника Алтайского округа. Новые объездчики вместо присяги давали подписку о подчинении Временному правительству и своим законным начальникам. При этом они должны были исполнять все обязанности по службе и отвечать за свои действия наравне с постоянной стражей и пользоваться всеми правами и преимуществами своего служебного положения. Работа такой временной лесной стражи находилась под контролем сельских и волостных земельных комитетов. Данные решения были вынужденными и лишь юридически закрепили фактически сложившееся положение, когда лесная стража могла быть назначена и уволена без согласия лесничего властью местных коллегиальных органов.

К началу 1918 г. практически по всем лесничествам Алтайской и Томской губерний ощущался некомплект лесников и объездчиков, а на тех, кто продолжал нести службу, по отзывам лесничих, рассчитывать не приходилось. Должности лесной стражи в большинстве случаев занимали случайные люди, нанимавшиеся на короткий срок и старавшиеся использовать служебные полномочия с максимальной для себя выгодой. Администрация возлагала большие надежды на начавшуюся в 1918 г. демобилизацию военнослужащих, среди которых были лесники и объездчики, начинавшие службу еще до революции. Было необходимо заменить «малоопытных и слабых по физическому состоянию здоровья лиц, принятых на службу за отсутствием соответствующих кандидатов по обстоятельствам военного времени, старыми, испытанными и знающими дело» [16. Л. 3]. Увольняемым временным объездчикам выплачивалась компенсация в размере месячного оклада жалования.

После установления советской власти была предпринята попытка повсеместного введения выборной народной лесной стражи. Она должна была назначаться и действовать от имени народа и под его контролем. Каждый гражданин, желавший занять должность объездчика, мог подать прошение в местный волостной исполнительный комитет, прилагая одобрительный приговор односельчан. Была разработана процедура комплектования должностей лесной стражи без участия лесной администрации властью местных земельно-лесных управ - коллегиальных органов, управлявших лесничествами. Рекомендовать кандидата на службу должен был волостной исполком, собирая сведения о кандидате и отбирая от него подписку о желании посвятить себя охране леса, получившего статус общенародного достояния, и беспрекословно исполнять законные требования и поручения земельно-лесной управы лесничества. Подписка заменяла собой присягу, которую приносил лесник или объездчик при поступлении на службу в дореволюционный период. Окончательное решение о готовности кандидата к несению службы выносила земельно-лесная управа, которая определяла уровень его грамотности и физические данные [6. Л. 19-19 об.].

Право на ношение оружия за объездчиками было оставлено. Нагрудные знаки, являвшиеся традиционным символом власти лесника и объездчика, планировалось заменить красной нарукавной повязкой, носимой на левой руке, с белыми буквами Н.Л.С. (народная лесная стража). Однако последнее, казалось бы, самое простое нововведение оказалось весьма проблематично реализовать. От лесничих стали поступать рапорты, в которых указывалось на полное отсутствие материала для изготовления нарукавных повязок [8. Л. 6].

Выборная народная стража должна была проживать в своих же деревнях и селах, что было вызвано желанием сэкономить на строительстве кордонов. Более того, со стражников, проживавших в казенных квартирах, стал удерживаться определенный процент жалования. В результате лесники и объездчики в массовом порядке оставляли кордоны и переселялись в деревни. Мнимая экономия и не обоснованное интересами лесного хозяйства желание «приблизить» лесную стражу к народу привели к тому, что она попала в полную зависимость от местного населения. Выборная лесная стража отличалась крайне низким уровнем компетентности, а также полным отсутствием заинтересованности в сохранении лесов. В этом отношении показателен случай, произошедший в одном из лесничеств и нашедший отражение в служеб- 
ной переписке. На замечание лесничего о недостаточной бдительности при охране леса выборный объездчик совершенно спокойно заметил: «Сапоги сносим, а они стоят 60 рублей» [4. Л. 114 об.].

Неоднозначным решением советской власти стало также фактическое упразднение должности старшего объездчика в Алтайской губернии, последовавшее в результате установления всем объездчикам одинакового месячного оклада в размере 150 руб. Однако уравнивание в жаловании не означало, что младшие объездчики автоматически приобретали требуемую квалификацию. Необходимость наблюдения за правильным исполнением возложенных на младших объездчиков обязанностей, выдачей лесорубных билетов, оценкой произведенных порубок сохранялась, поэтому было принято решение наиболее «опытных, грамотных и энергичных» объездчиков освободить от охраны объездов и, установив суточную доплату (1 руб.), возложить на них выполнение ряда лесохозяйственных операций [6. Л. 27].

Предложенная схема не продержалась и месяца: упразднение должности старших объездчиков негативно сказалось на работоспособности лесной стражи. Решением коллегии Алтайского губернского отдела по управлению имуществами республики в конце мая 1918 г. было принято решение восстановить деление объездчиков на старших и младших с размером окладов 180 и 150 руб. в месяц соответственно (оклад месячного жалования лесничего составлял 5000 руб.) [Там же. Л. 35].

Вторым важнейшим направлением лесоохранной деятельности на юге Западной Сибири в рассматриваемый период являлась борьба с лесными пожарами. Ослабление надзора за лесами со стороны лесной стражи, отказы местного населения от участия в тушении пожаров в лесах вкупе с неблагоприятными природными условиями резко обострили проблему сохранения лесов от огня весной-летом 1917 г. Кратковременное установление советской власти в Западной Сибири совпало с началом нового пожароопасного сезона 1918 г. Это обстоятельство предопределило необходимость принятия конкретных мер по предупреждению и ликвидации лесных пожаров.

Советская власть не стала вносить коррективы в основополагающие принципы обеспечения пожарной безопасности в лесах. В частности, было подтверждено требование о рубке и вывозке заготовленного леса из боровых и степных дач исключительно зимой, т.е. вне пожароопасного сезона. На период повышенной пожарной опасности должны были закрываться лесные дороги, а летняя заготовка леса допускалась только в исключительных случаях. Однако на крупных лесозаготовителей это ограничение не распространялось, если имелись договоры, «гарантирующие строгое соблюдение всех предосторожностей против возникновения пожаров, а также уплату убытков» [Там же. Л. 26-26 об.]. Заготовка древесины была объявлена важнейшей задачей всех местных советских органов, поэтому любые ограничения действий лесозаготовителей рассматривались как контрреволюционная деятельность.

Традиционно основная угроза пожарной безопасности лесам в весенний период исходила от сель- хозпалов, запускаемых крестьянами на своих сенокосных и пашенных участках, прилегающих к лесу или находящихся в границах лесных дач. Выжигание прошлогодней травы в весенний период считалось сибирскими крестьянами обязательным элементом агрономической технологии. Очень часто при проведении палов огонь «упускался» и заходил в лес, провоцируя начало лесного пожара. Чаще всего страдали от таких пожаров ленточные сосновые боры, природной особенностью которых являлась повышенная горимость, обусловленная большим количеством жарких дней, сухостью воздуха, постоянными сильными юго-западными ветрами засушливого характера, соседством со степями и преобладанием хвойных лесов [17. С. 126]. Единственным способом борьбы с распространением напольных пожаров было проведение опалок - контролируемого выжигания прошлогодней травы на границах лесных участков или внутри лесных дач.

В конце апреля 1918 г. в Алтайской и Томской губерниях были разработаны и разосланы на места в форме обязательных постановлений губернских земельных отделов подробные правила проведения опалок, в которых устанавливались порядок и процедура проведения этого противопожарного мероприятия [6. Л. 32-32 об.; 18. Л. 1]. Общее наблюдение за выжиганием травы было возложено на волостные исполкомы, к которым должны были обращаться сельские общества за разрешением произвести опалку на своих участках. Исполком должен был назначить время проведения опалки и ответственных лиц, обязанных лично на местах следить за выжиганием травы. Виновные в несоблюдении правил опалки должны были привлекаться к ответственности.

На исполкомы возлагались осуществление других противопожарных мероприятий, а также обязанность «немедленно и совершенно устранять всякого рода трения на почве предупреждения и тушения пожаров между лесничествами и населением» [6. Л. 21 об.]. Лесничие лишились властных полномочий по организации тушения лесных пожаров, сохранив за собой чисто технические функции по непосредственному руководству ликвидацией огня.

Волостные и сельские власти были обязаны оказывать всемерную поддержку земельно-лесным управам в предупреждении или немедленной локализации уже начавшихся лесных пожаров. Охрана лесов от пожаров была названа «нравственным долгом» всего населения, проживавшего вблизи лесных дач и пользовавшегося лесными материалами из них. Норма об оплате труда населения на тушении лесных пожаров была оставлена, однако при установлении размера вознаграждения за тушение пожаров учитывался «нравственный долг» охраны лесных дач со стороны сельских обществ, пользующихся лесными материалами. Это означало, что не слишком высокий размер оплаты труда участвовавших в тушении пожаров компенсировался предоставлением им права получения древесины из близлежащих лесных дач.

В Алтайской губернии размер оплаты труда взрослого мужчины составлял 3-4 руб. в день (в зависимости от месяца), а женщин и подростков - на один 
рубль меньше. Также предусматривалась доплата за использование лошади в размере 2-3 руб. [6. Л. 20 20 об.]. Поденная плата являлась еще и компенсацией за использование пожарными своего инвентаря и корма для лошадей. По сравнению с ранее действовавшей таксой 1916 г. размер оплаты был увеличен в несколько раз, что стало отражением значительного удорожания жизни и обесценивания денег. В Томской губернии пожарные таксы, определявшие размер вознаграждения лицам, участвующим в тушении лесных пожаров, были несколько выше, что объясняется преобладанием там труднодоступных таежных лесов и меньшей плотностью населения. Так, взрослый мужчина мог получить за участие в тушении пожара от 4 руб. 50 коп. до 6 руб. в день (в зависимости от месяца), женщины и подростки - от 3 руб. до 4 руб. 50 коп. Доплата за использование лошади составляла от 3 руб. до 4 руб. 50 коп. Предусматривались доплаты в таких же размерах тем работникам, которые прибывали из сел и деревень, находившихся на расстоянии далее 35 верст от места тушения пожара [18. Л. 8].

Говоря о размере оплаты труда на тушении лесных пожаров, необходимо понимать уровень цен на продовольственные и промышленные товары, а также различные услуги, существовавший в рассматриваемый период. По данным региональной периодической печати первой половины 1918 г. («Западная Сибирь», «Бийская правда», «Сибирская земская деревня», «Алтайский луч», «Алтай» и др.), твердая цена на говядину составляла в зависимости от сорта от 16 до 29 руб. за пуд; краковская колбаса первого сорта в розничной продаже стоила 2 руб. 20 коп. за фунт; стоимость папирос первого сорта составляла 3 руб. 50 коп. за пачку (50 шт.), махорки - 1 руб. 60 коп. за фунт; пуд сена оценивался в 2 руб. 50 коп.; за 60 коп. можно было пообедать в специальной столовой для безработных, а за 1 руб. приобрести чайную чашку самогона; один час езды на извозчике мог обойтись в 3 руб. 50 коп. Цены на товары первой необходимости могли меняться практически каждый день, преимущественно в сторону увеличения. При определении ценности денег необходимо также учитывать фактор «твердых цен», которые устанавливало правительство на продовольственные товары в условиях глубокого финансового кризиса и гиперинфляции. Как правило, реальные рыночные цены могли во много раз превышать твердые [19. С. 91].

Сельские исполнительные комитеты обязывались немедленно отправлять достаточное количество граждан для тушения пожара со своим инвентарем, провизией и питьевой водой. Было оставлено без изменений правило, действовавшее в дореволюционный период, о порядке прибытия на тушение лиц, согласно которому проживавшие в пределах 35 верст прибывали в тот же день, жители отдаленных деревень - на следующий. В случае уклонения местных обществ от тушения предусматривалось сокращение или прекращение отпуска леса для их нужд. Однако подобные угрозы не могли существенно повлиять на динамику лесных пожаров. В это период участились умышленные поджоги с целью отвлечения лесной стражи от мест массовых порубок, а население продолжало отказываться тушить пожары.

Таким образом, преобразования советской власти в сфере лесного хозяйства были ориентированы на долгосрочную перспективу формирования общенародного лесного фонда, находящегося под управлением, надзором и охраной коллегиальных общественных структур. Охрана лесов рассматривалась как общественная обязанность, реализуемая каждым гражданином во имя общего блага. Организующей и направляющей силой в земельно-лесной отрасли должны были выступать местные советские органы, заменившие в этой роли земельные комитеты. За бывшей лесной администрацией оставались чисто технические функции поддержания, насколько это было возможно, правильного режима хозяйствования в лесах. Однако реализовать в полной мере программные установки центра в сфере земельно-лесной политики в регионе не удалось в силу кратковременности пребывания советов у власти, в связи с чем можно говорить лишь о точечных изменениях в сфере лесопользования и лесоохраны. Существенных изменений в лесоохранный механизм внесено не было. Реализация в Сибири декрета «О социализации земли» не привела к существенному увеличению объемов крестьянского землепользования, а также не предоставила крестьянам возможности неограниченного пользования лесами. Западносибирский лес рассматривался центром в качестве стратегического ресурса, поэтому допустить его бесконтрольное пользование, граничащее с уничтожением, власть не могла. Однако постепенная утрата авторитета советской власти среди крестьян способствовала её быстрому свержению летом 1918 г. Организационная модель лесоуправления и лесоохраны, основывавшаяся на принципе общенародной собственности на лес и коллегиальности, была отменена после прихода к власти Временного Сибирского правительства.

\section{ЛИТЕРАТУРА}

1. Собрание узаконений и распоряжений правительства за 1917-1918 гг. М., 1942

2. Гойхбарг А.Г. Советское земельное право. М., 1921

3. Ц-ч. В Западной Сибири // Западная Сибирь. 1918. № 3.

4. Государственный архив Алтайского края (далее - ГААК). Ф. 4. Оп. 1. Д. 540

5. Пасична Ю.Г. Первые законопроекты в сфере аграрной политики Временного правительства (март 1917 г.) // Вестник Оренбургского государственного педагогического университета: электронный научный журнал. 2014. № 1 (9).

6. ГААК. Ф. 73. Оп. 2. Д. 10.

7. Тяпкин М.О. Льготные отпуски древесины населению как элемент системы охраны лесов юга Западной Сибири в первой четверти ХХ в. // Вестник Томского государственного университета. 2016. № 411.

8. ГААК. Ф. 133. Оп. 1. Д. 14

9. ГААК. Ф. 133. Оп. 1. Д. 9.

10. Государственный архив Томской области (далее - ГАТО). Ф. 241. Оп. 1. Д. 117. 
11. ГААК. Ф. 4. ОП. 1. Д. 4786.

12. ГААК. Ф. 126. Оп. 1. Д. 19.

13. Алтайский государственный краеведческий музей. Ф. Р-3. Оп. 1. Д. 3.

14. ГАТО. Ф. 3. Оп. 45. Д. 1299.

15. ГАТО. Ф. 241. Оп. 1. Д. 123.

16. ГАТО. Ф. 241 . Оп. 1. Д. 115.

17. Бугаев В.А., Косарев Н.Г. Лесное хозяйство ленточных боров Алтайского края. Барнаул, 1988.

18. ГАТО. Ф. 240. Оп. 1. Д. 855.

19. Тишкина А.В. Товары и цены в Советской России в 1917-1921 гг. (на материалах Среднего Поволжья) // Известия Пензенского государственного педагогического университета. 2008. № 6 (10).

Статья представлена научной редакцией «История» 27 февраля 2017 г.

FOREST CONSERVATION IN THE SOUTH OF WESTERN SIBERIA IN THE FIRST HALF OF 1918

Vestnik Tomskogo gosudarstvennogo universiteta - Tomsk State University Journal, 2017, 417, 169-175.

DOI: $10.17223 / 15617793 / 417 / 24$

Mikhail O. Tyapkin, Barnaul Law Institute of the Ministry of Internal Affairs of the Russian Federation (Barnaul, Russian Federation). E-mail: tyapkin@rambler.ru

Keywords: forest conservation; nationalization; unauthorized felling of wood; wildfires; national forest guards; Soviet power.

Regional peculiarities of organization and implementation of forest protection activities are of real significance for the history of Russian forestry. This article aims to research the main directions of the Soviet power activity concerning forest protection in the south of Western Siberia in the first half of 1918. The complex of the archive and published data from regional archives and libraries is the basis of the article. In the first half of 1918, the Soviet power was established and a new state forest policy began to be implemented. All forests were nationalized and declared national property; any property on woods was canceled. The state began to take care of the condition of forests. Revolutionary events and change of the political regime in the country led to a large-scale social and economic crisis which influenced the forest industry. The number of unauthorized fellings of the wood dramatically increased, and complete destruction threatened valuable forests. Weakened control of woods also caused an increase of forest fires. Forest protection from fires and unauthorized fellings was of real importance for activities of the central and local authorities, of forest officers. Forest protection was declared a general civil duty and non-fulfilment of it caused legal responsibility. The local population had to carry out fire-prevention measures, take part in extinguishing of forest fires and protecting woods from illegal use. Control of forest exploitation and organization of forest protection was assigned to local authorities of the Soviet power as represented by land departments of executive committees. Forest officers did not solve major issues of forest management, first of all, related to the supply of the population and other consumers with wood. Forest management began to base on the principle of collective leadership. The new principles of the organization of forest protection activities were fixed in several regulations of the Soviet government, the most important of which was the decree "About the Woods" passed in May, 1918. Due to the short period of the activity of the Soviet government in the south of Western Siberia in this period, the new model of forest management only began to take shape. After accession to power of the Provisional Siberian Government in the early summer of 1918, all decisions of the Soviet government, including forest protection laws, were canceled.

\section{REFERENCES}

1. Council of People's Commissars. (1942) Sobranie uzakoneniy i rasporyazheniy pravitel'stva za 1917-1918 gg. [Collection of laws and orders of the government for 1917-1918]. Moscow: Upravlenie delami SovNarkKoma SSSR.

2. Goykhbarg, A.G. (1921) Sovetskoe zemel'noe pravo [Soviet land law]. Moscow: Gosudarstvennoe izdatel'stvo.

3. Ts-ch. (1918) V Zapadnoy Sibiri [In Western Siberia]. Zapadnaya Sibir'. 3.

4. State Archive of Altai Krai (GAAK). Fund 4. List 1. File 540. (In Russian).

5. Pasichna, Yu.G. (2014) Pervye zakonoproekty v sfere agrarnoy politiki Vremennogo pravitel'stva (mart $1917 \mathrm{~g}$.) [The first bills in the field of agrarian policy of the Provisional Government (March 1917)]. Vestnik Orenburgskogo gosudarstvennogo pedagogicheskogo universiteta: elektronnyy nauchnyy zhurnal. 1 (9).

6. State Archive of Altai Krai (GAAK). Fund 73. List 2. File 10. (In Russian).

7. Tyapkin, M.O. (2016) Preferential releases of wood to the population as part of the system of forest protection in the south of Western Siberia in the first quarter of the 20th century. Vestnik Tomskogo gosudarstvennogo universiteta - Tomsk State University Journal. 411. pp. 165-170. (In Russian). DOI: 10.17223/15617793/411/22

8. State Archive of Altai Krai (GAAK). Fund 133. List 1. File 14. (In Russian).

9. State Archive of Altai Krai (GAAK). Fund 133. List 1. File 9. (In Russian).

10. State Archive of Tomsk Oblast (GATO). Fund 241. List 1. File 117. (In Russian).

11. State Archive of Altai Krai (GAAK). Fund 4. List 1. File 4786. (In Russian).

12. State Archive of Altai Krai (GAAK). Fund 126. List 1. File 19. (In Russian).

13. Altai State Museum of Local Lore. Fund R-3. List 1. File 3. (In Russian).

14. State Archive of Tomsk Oblast (GATO). Fund 3. List 45. File 1299. (In Russian).

15. State Archive of Tomsk Oblast (GATO). Fund 241. List 1. File 123. (In Russian)

16. State Archive of Tomsk Oblast (GATO). Fund 241. List 1. File 115. (In Russian).

17. Bugaev, V.A. \& Kosarev, N.G. (1988) Lesnoe khozyaystvo lentochnykh borov Altayskogo kraya [Forestry of the belt forests of Altai Krai]. Barnaul.

18. State Archive of Tomsk Oblast (GATO). Fund 240. List 1. File 855. (In Russian).

19. Tishkina, A.V. (2008) Tovary i tseny v Sovetskoy Rossii v 1917-1921 gg. (na materialakh Srednego Povolzh'ya) [Goods and prices in Soviet Russia in 1917-1921. (On the materials of the Middle Volga region)]. Izvestiya Penzenskogo gosudarstvennogo pedagogicheskogo universiteta. $6(10)$. 